\title{
Manila clam, Ruditapes philippinarum Cathepsin D: Molecular analysis and immune response against brown ring disease causing Vibrio tapetis challenge
}

\author{
Udeni Menike, Krishan Ariyasiri', Jin-young Choi, Youngdeuk Lee ${ }^{2}$, W.D.N. \\ Wickramaarachchi ${ }^{3}$, H.K.A. Premachandra ${ }^{3}$, Jehee Lee $^{3}$, Mahanama De Zoysa \\ College of Veterinary Medicine and Research Institute of Veterinary Medicine, Chungnam National University, Daejeon, 305-764 \\ ${ }^{1}$ Department of Biology, Chungnam National University, Daejeon, 305-764 \\ ${ }^{2}$ Korea Institute of Ocean Science Technology, Ansan, 426-744 \\ ${ }^{3}$ Department of Marine Life Sciences, Jeju National University, Jeju, 690-756
}

\begin{abstract}
Cathepsins are lysosomal /cysteine proteases belong to papain family ( $\mathrm{C} 1$ family) that is involved in intracellular protein degradation, antigen processing, hormone maturation, and immune responses. In this study, member of cathepsin family was identified from Manila clam (Mc-Cathepsin D) and investigated the immune response against brown ring disease (BRD) causing Vibrio tapetis challenge. The identified Mc-Cathepsin $D$ gene encodes characteristic features typical for the cathepsin family including eukaryotic and viral aspartyl protease signature domain and two highly conserved active sites $\left({ }^{84}\right.$ VVFDTGSSNLWV $^{95}$ and ${ }^{270}$ IADTGTSLLAG $\left.{ }^{281}\right)$. Moreover, MC-Cathepsin D shows higher identity values (-50-70\%) and conserved amino acids with known cathepsin D members. Transcriptional results (by quantitative real-time RT-PCR) showed that Mc-Cathepsin D was expressed at higher levels in gills and hemocytes than mantle, adductor muscle, foot, and siphon. After the $V$. tapetis challenge under laboratory conditions, Mc-Cathepsin D mRNA was up-regulated in gills and hemocytes. Present study indicates that Mc-Cathepsin $D$ is constitutively expressed in different tissues and potentially inducible when infecting BRD by $V$. tapetis. It is further suggesting that Mc-Cathepsin D may be involved in multiple role including immune response reactions against BRD.
\end{abstract}

Keywords: Brown ring disease, Manila clam (Ruditapes philipphinarum), Cathepsin D, V. tapetis.

\section{Introduction}

Manila clam, Ruditapes philippinarum is considered as one of the main species of marine bivalves (phylum-mollusk) and commonly cultured in Korea,

Received: June 18, 2013; Accepted: June 26, 2013

Corresponding author : De Zoysa

Tel: +82 (42) 821-6795 e-mail: mahanama@cnu.ac.kr Corresponding author: Jehee Lee

Tel: +82 (64) 754-3472 e-mail: jehee@jejunu.ac.kr $1225-3480 / 24482$

This is an Open Access article distributed under the terms of the Creative Commons Attribution Non-Commercial License with permits unrestricted non-commercial use, distribution, and reproducibility in any medium, provided the original work is properly cited.
China, and Japan. The global aquaculture production of Manila clam has been increasing during last few decades (FAO, 2012). However, it was reported that gradual reduction of clams in Korean waters due to many reasons including limited or loss of clam beds, environmental pollutants, intensive culture systems, and infectious diseases (Park et al., 1999; Park and Choi, 2004). Mass mortality of Manila clam has been reported annually on major clam beds in Korea that are often linked with high level of bacterial or parasitic (eg. perkinsus) infections. BRD is one of the major diseases in Manila clam which results significant economic losses to industry (Paillard et al., 1994; Paillard et al., 1995). Gram negative marine bacterium $V$. tapetis that was initially identified as 
Vibrio P1 is the etiological agent of BRD (Paillard and Maes, 1990; Borrego et al., 1996; Allam et al., 2002). Park et al., (2006) reported the first evidence of BRD infection from the clam samples collected at Anmyeondo Island, west coast of Korea. Pathogenicity of $V$. tapetis is varied with different stocks and environmental conditions such as salinity and temperature (Paillard et al., 2004). Therefore, investigating immune capacity of clam is important to select stocks with BRD resistance and fast recovery process after infection. Also, disease resistant capacity and host immune responses are directly related with transcriptional level of immune functional genes during the pathogenic infection.

Cathepsins are lysosomal /cysteine proteases belong to papain family (C1 family) that is involved in intracellular protein degradation (Bond et al., 1987), antigen processing (Hsing and Rudensky, 2005), hormone maturation (Yasothornsrikul et al., 2003) and immune responses (Dixit et al., 2008). Wide array of cathepsins has been identified form various organisms and they are classified based on sequence homology, specific or conserved amino acid motifs (cysteine, serine, aspartate), and tissue distribution pattern. According to the Bühling et al., (2002) cathepsins can be divided in to 3 classes based on enzyme class or lysosomal proteolytic (cathepsins: B, C, H, L, S, F, K, O, V, W, and $\mathrm{X}$ ), systeine proteases (cathepsins: $\mathrm{A}$ and $\mathrm{G}$ ) and aspartic proteases (cathepsins: D and E). To date, there is no details information on cathepsin family genes and their immune role from Manila clam. Therefore, studies on cathepsin genes and transcriptional responses against $V$. tapetis challenge could be supported to understand the immune response and BRD resistance capacities of clams.

In this study, we have identified and molecular characterized the Cathepsin D from Manila clam cathepsin family. To understand the expression profiles and immune role of Mc-Cathepsin D tissue specific mRNA expression and transcriptional regulation were investigated after bacteria $V$. tapetis challenge.

\section{Materials and methods}

\section{Analysis of Mc-Cathepsin D}

We have established the Manila clam transcriptome using pyrosequencing of normalized cDNA (Lee et al., 2013). Putative sequence that had homology to known cathepsins was identified by BLAST analysis and named as Mc-Cathepsin D. DNAssist (version 2.2) was used to determine the open reading frame (ORF) and encoded amino acid sequence. Functional domains were determined by using NCBI conserved domain database and Simple Modular Architecture Research Tool (SMART) program (http://smart.embl-heidelberg.de). The identity percentage of Mc-Cathepsin D with known cathepsin members was calculated using ClustalW2 analysis (Thompson et al., 1994). The phylogenetic tree was constructed by Neighbor-Joining method using molecular evolutionary genetic analysis (MEGA) software (version 5.05) with bootstrapping values taken from 1000 replicates (Kumar et al., 2004).

\section{Vibrio tapetis challenge of Manila clam}

Clams with an average size of $35 \pm 5 \mathrm{~mm}$ were collected from the eastern coastal area of Jeju Island and maintained in $80 \mathrm{~L}$ tanks of aerated sand-filtered seawater with $34 \pm 1 \%$ salinity and $20 \pm 1^{\circ} \mathrm{C}$. Clams were acclimatized to laboratory conditions for seven days prior to the experiment. In order to evaluate the tissue specific expression of Mc-Cathepsin D, gill, mantle, adductor muscle, foot, and siphon were isolated from five unchallenged individuals. Hemolymph (0.5-1 mL/clam) was also collected from each animal using a sterile syringe; hemocytes were immediately harvested by centrifugation at $3000 \mathrm{x} \mathrm{g}$ for $10 \mathrm{~min}$ at $4^{\circ} \mathrm{C}$. In order to determine the immune response of $\mathrm{Mc}$-Cathepsin $\mathrm{D}$, in vivo challenge was carried out using Gram-negative bacteria $V$. tapetis which was suspended in $0.9 \%$ saline. Clams were randomly chosen for intramuscular injection of $100 \mu \mathrm{L}$ of $V$. tapetis $\left(1.9 \times 10^{8}\right.$ cells/clam). Saline (0.9\%) injected $(100 \mu \mathrm{L})$ clams were used as controls. The total RNA was extracted from $200 \mathrm{mg}$ (40 mg each from 5 individual) of pooled tissue sample and hemocyte samples using the Qiazol reagent (Qiagen). RNA samples were diluted to $1 \mu \mathrm{g} / \mu \mathrm{L}$ concentration and used for cDNA synthesis using PrimeScript ${ }^{\mathrm{TM}}$ first-strand cDNA synthesis kit (Takara). The cDNA 


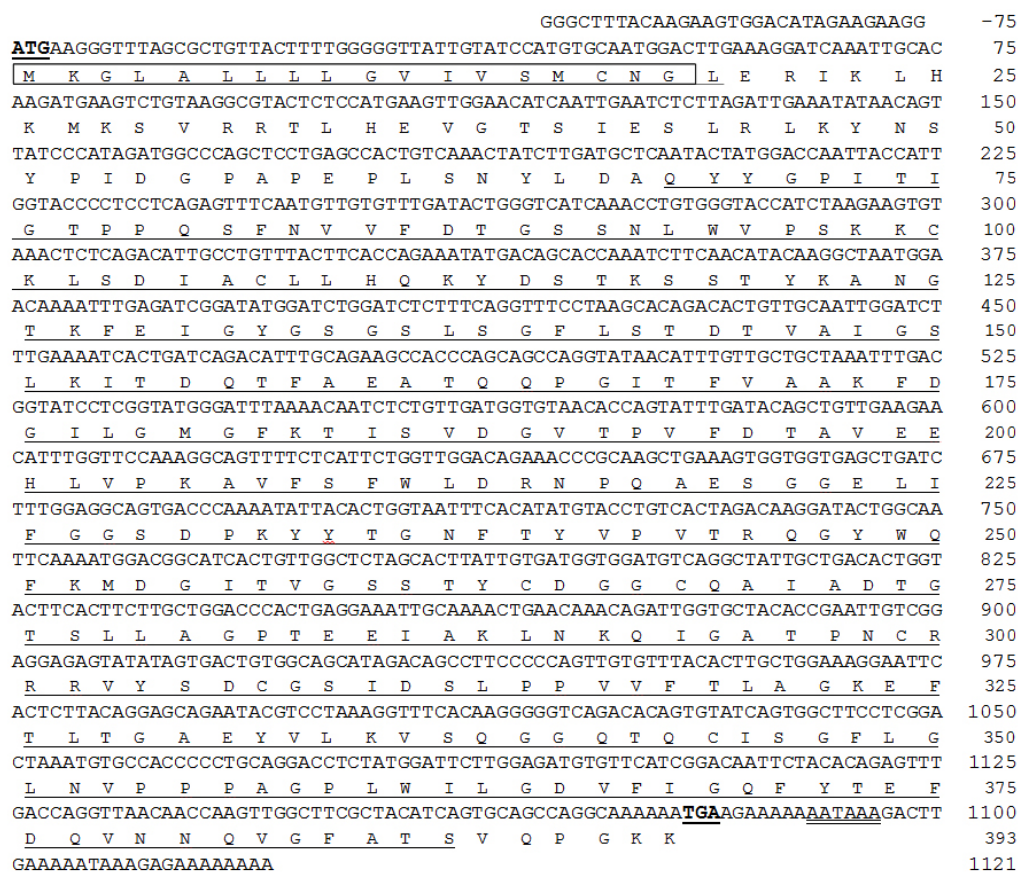

Fig. 1. The nucleotide and deduced amino acid sequences of Mc-Cathepsin $D$ cDNA. The start (ATG) and stop (TGA) codons are underlined and with bold face. Characteristic eukaryotic aspartyl protease signature domain is underlined. The predicted signal peptide sequence is in box. Polyadenylation site is double underlined.

synthesis reaction was carried out according to the manufacturer's instructions (Takara). The synthesized cDNA was diluted in 40 fold before used in transcriptional analysis.

\section{Analysis of Immune response of Mc-Cathepsin D}

Mc-Cathepsin D mRNA expression (under un-challenged and $V$. tapetis challenged) was determined by quantitative real time RT-PCR (qRT-PCR). The gene specific primers of Mc-Cathepsin D (forward primer 5'-AGTGGTGGTGAGCTGATCTTTGGA-3' and reverse primer 5'-ATTTCCTCAGTGGGTCCAGCAAGA-3') were used. The gene coding for clam $\beta$-actin was amplified using specific primers (Forward 5'-CTC CCT TGA GAA GAG CTA CGA-3' and reverse 5'-GAT ACC AGC AGA TTC CAT ACC C-3') as an internal control. The qRT-PCR assay was performed according to our previous method as described (Lee et al., 2013) and the relative expression fold was determined by the Livak $2^{-\triangle \triangle \mathrm{CT}}$ method (Livak et al., 2011). To determine the tissue-specific expression (tissue distribution) of
Mc-Cathepsin D, expression level in other tissues was compared with that of hemocytes. Transcriptional change of Mc-Cathepsin D after bacteria challenge was investigated in hemocytes and gill tissue by time course experiment. Transcriptional response of Mc-Cathepsin D was determined by comparing the expressional level in gills and hemocytes of $V$. tapetis challenged animals and saline injected controls.

\section{Results}

\section{Characterization of Mc-Cathepsin D cDNA}

Member of cathepsin family (Mc-Cathepsin D) was identified from Manila clam transcriptome analysis. Nucleotide and amino acid sequences of Mc-Cathepsin $\mathrm{D}$ are shown in the fig. 1 . The full length $(1252 \mathrm{bp})$ of Mc-Cathepsin D consists of 1179 bp open reading frame (ORF) which codes for 393 amino acids protein. Predicted molecular mass of Mc-Cathepsin D was 42 $\mathrm{kD}$ and it showed 6.1 isoelectric point. The $5^{\prime}$ and $3^{\prime}$ un-translated regions (UTR) were $31 \mathrm{bp}$ and $46 \mathrm{bp}$, 
Manila clam, Ruditapes philippinarum Cathepsin D: Molecular analysis and immune response against brown ring disease causing Vibrio tapetis challenge

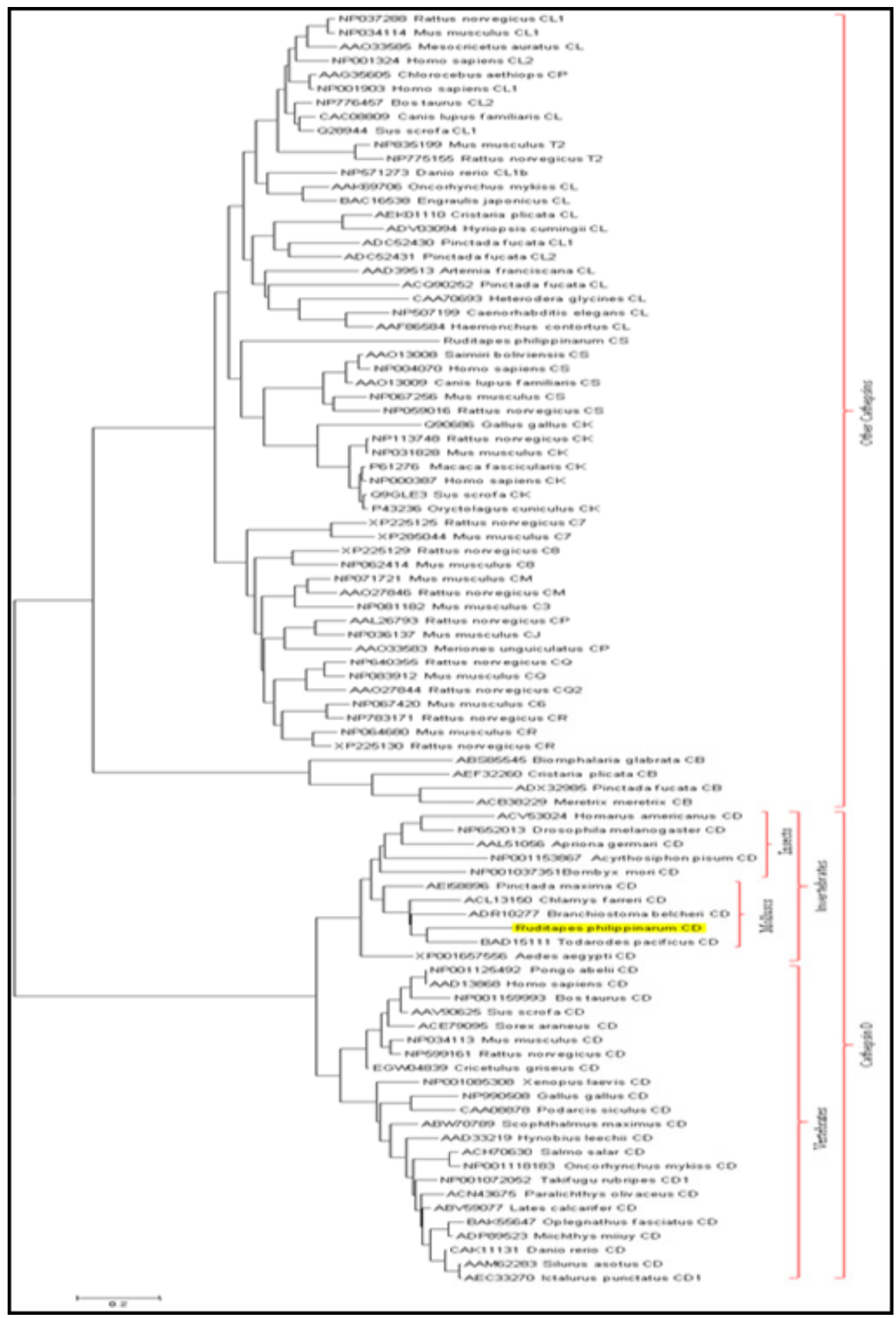

Fig. 2. Phylogenetic analysis of Mc-Cathepsin D. The GenBank accession number of each sequence is indicated with the species names. 
respectively. Eight cysteine (C) residues in the amino acid sequence were identified and then predicted 4 disulfide bonds $\left(\mathrm{C}_{16}-\mathrm{C}_{264}, \quad \mathrm{C}_{100}-\mathrm{C}_{107}, \quad \mathrm{C}_{268}-\mathrm{C}_{299}\right.$, and $\mathrm{C}_{307}-\mathrm{C}_{344}$ ). Signal $\mathrm{P}$ prediction results showed that it has N-terminal signal peptide sequence containing 18 amino acids. Motif scan analysis showed that characteristic eukaryotic aspartyl protease domain (68 to 387 amino acids) in the Mc-cathepsin D amino acid sequence. Additionally, two eukaryotic and viral aspartyl protease active sites at ${ }^{84}$ VVFDTGSSNLWV ${ }^{95}$ and ${ }^{27}$ OIADTGTSLLAG ${ }^{281}$ were identified in the main eukaryotic aspartyl protease domain. The polyadenylation site (AATAAA) was at 18 nucleotides upstream of the poly (A) tail.

Pairwise ClustalW analysis result showed that Mc-cathepsin D shares the highest identity (69.1\%) to Penguin wing oyster (Pterria penguin) cathepsin D. As expected it shares lower identity $(52.9 \%)$ with human cathepsin D. We constructed the phylogenetic tree with Mc- Cathepsin D and 91 known cathepsin family members (representing cathepsin D,L,T,S,K,M,P,J,Q,R and B) to understand the evolutional relationship between different species as well as different cathepsin family members (Fig. 2). Phylogenetic results showed that cathepsin genes are mainly grouped into vertebrate and invertebrate members. Cathepsins in vertebrate were shown in fish, amphibians, reptiles and birds while invertebrate cathepsins were divided into insects and molluscs. Mc-cathepsin D was grouped with mollusk cathepsin sub-family and it showed the closest relationship with squid Todarodes pacificus cathepsin D.

\section{Tissue specific expression and immune response of Mc-Cathepsin D}

Tissue-specific expression represents the level of Mc-Cathepsin D mRNA in selected tissues compared to that of hemocytes (Fig. 3). It showed that Mc-Ccathepsin D was highly expressed in gills than all other tissues such as, mantle, siphon, foot, adductor muscle, and hemocytes. However, the expression of Mc-Cathepsin D in the gill was almost 2.25 -fold higher than that of in the hemocyte.

Transcriptional change of Mc-Cathepsin D was

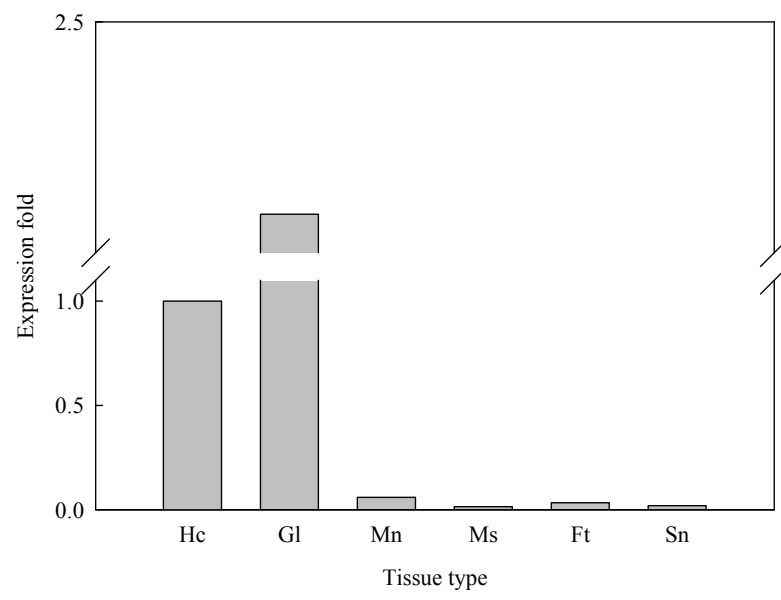

Fig. 3. Tissue-specific expression analysis of McCathepsin D mRNA. The relative mRNA expression of each tissue was normalized with expression in Hc-hemocyte; Gl-gills; Mn-, mantle; Ms-adductor muscle; Ft-foot; Sn-siphon.

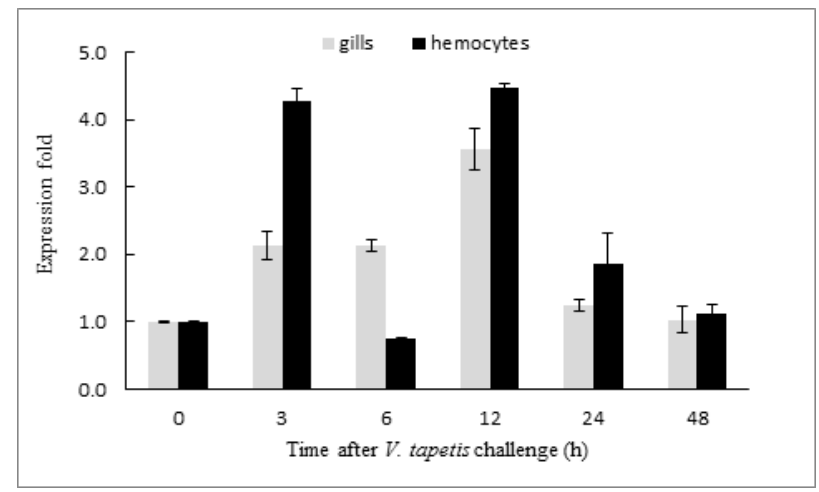

Fig. 4. Expression profiles of Mc-Cathepsin $D$ mRNA in manila clam gills and hemocytes after $V$. tapetis challenge. The relative level of expression for each time point was compared with that of saline injected control.

investigated in gills and hemocytes after $V$. tapetis challenge by time course qRT-PCR analysis (Fig. 4). In both gills and hemocytes, highest level of up regulation was at $12 \mathrm{~h}$ post challenge of $V$. tapetis compared to saline control. Except at $6 \mathrm{~h}$ post challenge, Mc-Cathepsin D expression was higher at all the time points in gills and hemocytes. However, gradual decrease of Mc-Cathepsin D expression (but higher that $0 \mathrm{~h}$ ) was recorded at $24 \mathrm{~h}$ and $48 \mathrm{~h}$ than at $12 \mathrm{~h}$ post challenge. As expected expression level of Mc-Cathepsin D in gills and hemocytes was varied with the post challenge time points in this study. 


\section{Discussion}

In the present study, we report the identification, molecular characterization, immune response of cathepsin family member (Cathepsin D) from Manila clam. The cathepsin family genes share several characteristic features including papain family cysteine protease domain, and eukaryotic thiol protease active sites (cysteine, asparagine, histidine) that play crucial role in the formation and stabilization these enzymes (Lecaille et al., 2002). The identified Mc-Cathepsin D gene encodes characteristic features typical of the cathepsin family including eukaryotic and viral aspartyl protease signature domain and two highly conserved active sites $\left({ }^{84}\right.$ VVFDTGSSNLWV $^{95}$ and $\left.{ }^{270}{ }^{2}{ }_{A D T G T S L L A G G}{ }^{281}\right)$. Moreover, MC-Cathepsin D shows higher amino acid identity values ( $\sim 50-70 \%)$ and conserved amino acids with known cathepsin D. Also, phylogenetic analysis revealed that Mc-Cathepsin D is positioned with other mollusk cathepsin D counterparts under invertebrate cathepsin family. Based on the molecular characterization, pairwise-multiple alignment and phylogenetic results, we could confirm that the identified cathepsin D from Manila clam is a newly member of the molluskcan cathepsin family.

Tissue specific expression of cathepsin isoforms in fish have been investigated broadly, but such information remains limited in mollusks. In un-challenged pearl oyster (Pinctada fucata) constitutive expression of cathepsin L was observed in digestive gland, gonad, haemocytes, gills, mantle, adductor muscle, and intestine (Ma et al., 2010). Ubiquitously expressed cathepsin D was identified in 11 tissues of un-challenged Paralichthys olivaceus (Zhang et al., 2004). Similarly, we identified MC-cathepsin D in all tested tissues of Manila clam. Constitutive expression of MC-Cathepsin D suggested that it may be involved actively in protease function. Cathepsin expression is known to be induced by several stimulators, such as LPS, virus, poly I:C (Zhang et al., 2004), bacteria Vibrio harveyi (Jia et al., 2009). Nair et al. (2005) reported the induction of cathepsin B and L expression level in sea urchin coelomocytes in response to LPS challenge. In mollusks, pearl oyster cathepsin L mRNA was shown both up and down regulated pattern in digestive gland after Vibrio alginolyticus challenge (Ma et al., 2010). We observed higher induction of Mc-Cathepsin D in gills and hemocytes after $V$. tapetis challenge; however, transcriptional induction has not occurred continuously throughout the $48 \mathrm{~h}$ post $V$. tapetis challenge. Since there is no reported expression data related to cathepsin D from any mollusks we are unable to compare present transcriptional responses in gills and hemocytes. The transcriptional differences of Mc-Cathepsin D in gills and hemocytes might be due to varied pathogenicity level and immune response capacity specific to tissues. Therefore, transcriptional variation of Mc-Cathepsin D required to be further investigated by conducting tissue specific and dose dependant immune challenge.

In conclusion, we identified cathepsin D cDNA sequences from Manila clam by applying a pyrosequencing technique. Mc-Cathepsin $\mathrm{D}$ is constitutively expressed in various tissues, suggesting they may be involved in a multifunctional role in Manila clams. Moreover, Mc-Cathepsin D gene showed the up-regulation when exposure to $V$. tapetis, indicating a potential role in Manila clam immune system specifically during BRD infection. At present, we are developing a bacterial expression system using E. coli to overproduce recombinant Mc-Cathepsin D that will facilitate further study of the functional role of this multifunctional gene.

\section{Acknowledgement}

This study was financially supported by research fund of Chungnam National University in 2011.

\section{REFERENCES}

Allam, B., Paillard, C. and Ford, S.E. (2002) Pathogenicity of Vibrio tapetis, the etiological agent of brown ring disease in clams. Diseases of Aquatic Organisms, 48: 221-231.

Bond, J.S. and Butler, P.E. (1987) Intracellular proteases. Annual Review of Biochemistry, 56: 333-364.

Borrego, J.J., Castro, D., Luque, A., Paillard, C., Maes, P., Garcia, M. T. and Ventosa, A. (1996) Vibrio 
tapetis sp. nov., the causative agent of the brown ring disease affecting cultured clams. International Journal of Systematic Bacteriology, 46: 480-484.

Bühling, F., Waldburg, N,m Krüger, S., Rocken, C., Wiesner, O., Weber, E., Welte, T. (2002) Expression of cathepsins B, H,K,L and S during human fetal lung development. Developmental Dynamics, 225: 14-21.

Dixit, A.K., Dixit, P. and Sharma, R.L. (2008) Immunodiagnostic/protective role of Cathepsin L cysteine proteinases secreted by Fasciola species. Veterinary Parasitology, 154: 177-184.

FAO. 2012 World review of fisheries and aquaculture. http://www.fao.org/docrep/016/i2727e/i2727e01.pdf

Hsing, L.C. and Rudensky, A.Y. (2005) The lysosomal cysteine proteases in MHC class II antigen presentation. Immunological Reviews, 207: 229-241.

Jia, A. and Zhang, X.H. (2009) Molecular cloning, characterization and expression analysis of cathepsin D from turbot Scophthalmus maximus. Fish \& Shellfish Immunology, 26: 606-613.

Kumar, S., Tamur,a K. and Nei, M. (2004) MEGA3: integrated software for molecular evolutionary genetics analysis and sequence alignment. Briefings in Bioinformatics, 5: 150-163.

Lecaille, F., Kaleta, J. and Bromme, D. (2002) Human and parasitic papain-like cysteine proteases: their role in physiology and pathology and recent developments in inhibitor design. Chemical Reviews, 102: 4459-4488.

Lee, Y., Wickamarachchi, W.D.N., Whang, I., O,h M., Umasuthan, N., De Zoysa, M., Oh, C., Kang, D.H. and Lee, J. (2013). Immune response-related gene expression profile of a novel molluscan $\mathrm{I} \kappa \mathrm{B}$ protein member from manila clam (Ruditapes philippinarum). Molecular Biology Reports, 40:1519-1527.

Livak, K.J. and Schmittgen, T.D. (2001) Analysis of relative gene expression data using real time quantitative PCR and the $2^{\triangle \Delta \mathrm{CT}}$ method. Methods, 25: $402-408$.

Maa, J., Zhang, D., Jiang, J., Cui, S., Pu, H. and Jiang, S. (2010) Molecular characterization and expression analysis of cathepsin L1 cysteine protease from pearl oyster Pinctada fucata. Fish \& Shellfish Immunology, 29: 501-507.

Nair, S.V., Del-Valle, H., Gross, P.S., Terwilliger, D.P. and Smith, L.C. (2005) Microarray analysis of coelomocyte gene expression in response to LPS in the sea urchin. Identification of unexpected immune diversity in an invertebrate. Physiological Genomics, 22:33-47.

Paillard, C. and Maes, P. (1990) Etiologie de la maladie de l'anneau brunchez Tapes philippinarum: pathogenicité d'un Vibrio sp. Comptes Rendus de I'Academie de Sciences, 310: 15-20.

Paillard, C. and Maes, P. (1994) The brown ring disease in manila clam, Ruditapes philippinarum: establishment of a classification system. Diseases of Aquatic Organisms, 19: 137-146.

Paillard, C. and Maes, P. (1995) The brown ring disease in the Manila clam, Ruditapes philippinarum. Ultrastructural alterations of the periostracal lamina. Journal of Invertebrate Pathology, 65: 91-100.

Paillard, C., Allam, B., Oubella, R. (2004) Effect of temperature on defense parameters in manila clam Ruditapes philippinarum challenged with Vibrio tapetis. Diseases of Aquatic Organisms, 59: 249-262.

Park K.I., Paillard, C., Chevalier, P.L. and Choi K.S. (2006) Report on the occurrence of brown ring disease (BRD) in Manila clam, Ruditapes philippinarum, on the west coast of Korea. Aquaculture, 255: 610-613.

Park, K.I. and Choi, K.S. (2004) Application of enzyme-linked immunosorbent assay for studying of reproduction in the Manila clam Ruditapes philippinarum (Mollusca: Bivalvia): I. Quantifying eggs. Aquaculture, 241: 667-687.

Park, K.I., Choi, K.S. and Choi, J.W. (1999) Epizootiology of Perkinsus sp. found in the Manila clam, Ruditapes philippinarum in Komsoe Bay, Korea. Journal of the Korean Fisheries Society, 32: 303-309.

Thompson, J.D., Higgins, D.G. and Gibson, T.J. (1994) CLUSTALW: improving the sensitivity of progressive multiple sequence alignment through sequence weighting, position-specific gap penalties and weight matrix choice. Nucleic Acids Research, 22: 4673-4680.

Yasothornsrikul, S., Greenbaum, D., Medzihradszky, K.F., Toneff, T., Bundey, R., Miller, R. et al.,. (2003) Cathepsin L in secretory vesicles functions as a prohormone-processing enzyme for production of the enkephalin peptide neurotransmitter. Proceedings of the National Academy of Sciences USA, 100: 9590-9595.

Zhang, F.T., Zhang, Y.B., Chen, Y.D., Zhu, R., Dong, C.W., Li, Y.Y., Zhang, Q.Y. and Gui, J.F. (2008) Expressional induction of Paralichthys olivaceus cathepsin B gene in response to virus, poly I:C and lipopolysaccharide. Fish \& Shellfish Immunology, 25: 542-549. 